\title{
What Do Professional Drivers Think about Their Profession? An Examination of Factors Contributing to the Driver Shortage
}

\author{
Chao Ji Hyland \\ Technological University Dublin, chao.ji@tudublin.ie \\ Declan Allen \\ Technological University Dublin, declan.allen@tudublin.ie
}

Follow this and additional works at: https://arrow.tudublin.ie/buschmanart

Part of the Business Administration, Management, and Operations Commons

\section{Recommended Citation}

Chao Ji-Hyland \& Declan Allen (2020) What do professional drivers think about their profession? An examination of factors contributing to the driver shortage, International Journal of Logistics Research and Applications, DOI: 10.1080/13675567.2020.1821623

This Article is brought to you for free and open access by the School of Management at ARROW@TU Dublin. It has been accepted for inclusion in Articles by an authorized administrator of ARROW@TU Dublin. For more information, please contact arrow.admin@tudublin.ie, aisling.coyne@tudublin.ie,gerard.connolly@tudublin.ie.

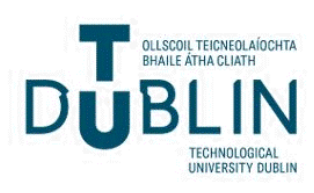




\title{
What Do Professional Drivers Think about Their Profession? An Examination of Factors Contributing to the Driver Shortage
}

\author{
Dr Chao Ji-Hyland BSc, MSc, PhD \\ Lecturer at the School of Management, \\ College of Business \\ Technological University Dublin \\ Email:chao.ji@tudublin.ie \\ Declan Allen BA (Hons) MBS, FCILT \\ Assistant Head of School of Management, \\ College of Business \\ Technological University Dublin \\ Declan.allen@tudublin.ie
}

\begin{abstract}
A shortage of qualified and available professional drivers in the Freight, Transport, Distribution and Logistics (FTDL) sector is becoming an area of increasing concern in Ireland, and across the European mainland. This paper applies a two-stage research approach to address the issues causing the driver shortage and to analyse contributing factors. The findings reveal that remuneration and salaries are detrimental to recruitment and retention. While driver wellbeing in terms of physical and mental health is a major issue, little support is provided for training and education. There is a relationship between a driver's age group and job satisfaction, and between the length of time working as a professional driver and job satisfaction. By uncovering the variety of factors that contribute to driver shortage, this research provides theoretical and practical knowledge in order to attract and retain a sustainable labour force of drivers required to sustain transportation services.
\end{abstract}

Keywords: Driver shortage, Job retention, Job turnover, Job satisfaction, Driver wellbeing 


\section{Introduction}

With the growth of the global supply chain and recent trends in improved automation, logistics and freight transport, the demand for drivers will be high (McKinnon et al., 2017, p27; Wrenn, 2017). Organisations are increasingly reliant on drivers for on-time deliveries, since in many sectors currently deliveries are viewed as an extension of the assembly line, with materials replenished using a just-in-time process. This synchronization of deliveries with production and distribution has been facilitated by the flexibility and speed of road transport (McKinnon, 2006). The entry-level logistics roles have lower pay and lower status than entry-level positions in other industries, creating an unattractive proposition for skilled workers (McKinnon et al., 2017, p111). Reports produced by the European Parliament (2017) indicate that drivers in the freight transport industry across Europe feel that the quality of various aspects of their role has deteriorated in recent years, including the standard of their working environment, income levels, the number of non-standard and standard working hours, and the skilled work involved, creating issues around driver retention.

The motivation behind this research is an industry study undertaken by the authors for the Freight Transport Association (FTA) in Ireland. For many industries, such as food and other manufacturing sectors, transportation represents the single most important element in logistics costs (Ballou, 2004), with road transportation representing almost 55 per cent of the total logistics cost (Wilson, 2013). Cost is not the single issue of concern, however, as supplychain reliability is more often than not the fundamental requirement of doing business. A shortage of qualified drivers has arisen as a critical area of difficulty over the last 15 years, hindering supply-chain performance in terms of both costs and reliability of service (Maloni et al., 2017). Academic literature regarding driver shortage covers a wide range of aspects such as logistics driver recruiting strategies (Lemay \& Taylor, 1988); driver turnover (Richard et al., 1995; Kramer, 2014); driver vocational training and education (Bag and Anand, 2014; Mello et al., 2018); driver retention (Cheng et al., 2014); and job satisfaction, commitment and psychological capital (Rakowski et al., 2014; Prockl et al., 2017; Mittal et al., 2018). In addition, a variety of papers, largely from the US, have been published on the logistics of driver shortages (Costello, 2017). Even though the drivers problem is global, none of the previous studies covers countries dealing with the same issue in other parts of the world, such as Europe. The freight transport and logistics industry on the island of Ireland faces a number of challenges and opportunities. Many reports and academic studies in Ireland prove this point. They include reports from the Expert Group on Future Skills 
Needs (EGFSN), Vocational Education and Training (VET), Further Education and Skills Service, and, in Irish, An tSeirbhís Oideachais Leanúnaigh agus Scileanna (SOLAS). Sweeney (2013) suggested that the "people dimension" has generally been neglected, with improvement initiatives focused solely on technology or information systems, and states that people are a vital aspect of supply-chain management in terms of building relationships and development; while other studies highlight future qualified driver skills needs, and encouragement of appropriate levels of training and recruitment (McKinnon, 2017; Staats et al., 2017; Mittal et al., 2018; Han et al., 2019). Consequently, there is a need to study drivers' perspectives on their profession in Ireland. To the best of our knowledge, our paper is the first of its kind to seek to analyse the driver shortage problem while considering the problem as a whole and with a specific focus on Ireland.

The rest of the paper is organised as follows: Section 2 outlines the theoretical background of this research; Section 3 discusses the research methodology adopted for this study; Section 4 outlines the data analysis and discusses the key findings; Section 5 highlights the theoretical and managerial implications of this study, and, finally, Section 6 presents recommendations and a conclusion together with research contributions, limitations and opportunities for further research.

\section{Literature Review}

Driver shortage is a longstanding issue for the logistics industry. Over the past few decades, academic papers have discussed the problem of the professional driver shortage and recommended strategies to deal with the issue. One of the earliest studies (Lemay and Taylor, 1988) discussed the issue of American truck driver hiring, examined different driver recruitment strategies, and suggested that closer relations with high schools and vocational programmes with internal career ladders for future drivers could help improve the driver shortage problem. Bag and Anand (2014) and Mello et al. (2018) argued that vocational training and education can enhance the skill of long-distance truck drivers. Cheng et al. (2014) and Staats et al. (2017) proposed a set of actions to improve hiring, training, and retaining practices by logistics companies for qualified drivers. Rakowski et al. (2014) found a strong positive relationship between job satisfaction, organisational commitment and psychological capital. Dubey and Gunasekaran (2015) identified the traits and skills of a truck driver needed for sustainable transportation. Mittal et al. (2018) recommended that government and trucking companies take several initiatives to improve the driver shortage situation and 
increase their driver retention and job attraction. To predict driver turnover, Kramer (2014) analysed the critical factors influencing high turnover of longdistance truck drivers, and found that vocational training and education can enhance the skills of long-distance truck drivers. For this paper, employee behavioural models developed by Maslow (1943), Herzberg (1959) and Hackman \& Oldham (1980) provided the central academically recognised frameworks for analysis of employee satisfaction and motivation. The literature provides evidence that workforce quality and talent management correlate with the performance of not only the organisation but also the entire supply chain (Wowak et al., 2013; Hohenstein et al., 2014). The research has identified the workforce as a critical success factor in supply-chain and logistics management, affecting cost and quality of service (Scott et al., 2015; Maloni et al., 2017). The literature addressing human resource management related specifically to driver shortage is relatively limited (Huo et al., 2015; LeMay and Keller; 2019). There is a need for research on the endemic issue of the shortage of qualified drivers (McKinnon, 2017; Staats et al., 2017; Mittal et al., 2018; Han et al., 2019).

\subsection{Drivers Shortage}

The academic literature on the driver shortage is both inconsistent and, in some cases contradictory, with several different aspects of the role presented as a key contributing factor to drivers leaving their positions. Despite recent trends in improved automation, logistics and freight transport currently relies on a quite particular skillset and range of capabilities, whether in management, administrative or driving roles. A lack of skilled personnel can, therefore, be hugely detrimental to an organisation's competitiveness in the market, due to reduced productivity and diminished quality of service (McKinnon et al., 2017; Berman, 2019). McKinnon (2006) noted that significant disruptions to road freight transport can have hugely detrimental effects on an economy, citing retail and food services, and healthcare as facets of the economy that rely heavily on road freight transport due to the time sensitivity of deliveries involved or the limited inventory held in these supply chains. Studies in countries such as China, India, the United States, the United Kingdom, Vietnam, and the Republic of South Korea have reported that businesses are having difficulty recruiting staff with the required skills in logistics/supply-chain management (McKinnon et al., 2017).

In Ireland, driving roles have been found to account for most of the vacant positions in the Freight, Transport, Distribution and Logistics (FTDL) sector (EGFSN, 2016) (Expert Group on Future Skills Needs, 2016). Reports produced 
by the European Parliament (2017) indicated that drivers in the freight transport industry across Europe felt that the quality of various aspects of their role had deteriorated in recent years, including the standard of their working environment, income levels, the amount of non-standard and standard working hours, and the skilled work involved, creating issues around driver retention. This comes at a time when organisations are increasingly relying on drivers for on-time deliveries, as in many sectors deliveries are now viewed as an extension of the assembly line, with materials replenished using a just-in-time process. This synchronisation of deliveries with production and distribution has been facilitated by the flexibility and speed of road transport (McKinnon, 2006). The Irish Road Haulage Association (IRHA) called on the Government to increase the number of non-EU work permits so that it could fill vacancies in 2018. Too few young drivers are entering the industry due to poor policies. The extent of driver shortage all across Europe cannot be overstated, with reports indicating that 150,000 driving positions remained vacant in 2018 across the continent, causing congestion and delays (King, 2019).

\subsection{Drivers Turnover}

It has been noted that significant driver turnover in an organisation generally reduces its ability to be competitive, due to the expensive recruitment processes incurred, equipment downtime and the disruption caused to delivery services (Min \& Emam, 2003). The academic literature on driver turnover has produced contrasting conclusions, with several different aspects of the role presented as the key contributing factor to drivers leaving their positions. Driver turnover plagues the industry, and it is particularly frustrating for managers as turnover influences costs and service, and contributes to the overall logistics performance (LeMay and Keller, 2019). The factors contributing to driver turnover have been identified in previous studies as including the age and education levels of drivers (Min \& Emam, 2003); professional relationship with managers (Celma et al., 2018); working conditions and job security (Maloni et al., 2017; Kudo et al., 2019); safety hazards (Viscelli, 2018); personal risk (Costello and Suarez, 2015; Douglas and Swartz, 2016), and job security (Kudo et al., 2019; Kubanova et al., 2020).

Furthermore, LeMay et al. (2013) argued that driver turnover also occurs where drivers feel they have been misled about what the role entails. Carriers with lower overall turnover would benefit the greatest through improvements in safety performance (Miller et al., 2017). Employee needs and wellbeing are also other objectives of international organisations such as the International Labour 
Organization, the European Union and the United Nations, as they all promote corporate social responsibility (Celma et al., 2018). Various academic articles based on wide-ranging disciplines highlight that job dissatisfaction is a factor that has a direct correlation with employee turnover intention (Alsaraireh et al., 2014; Wijngaards et al., 2019; Mittal et al., 2018).

\subsection{Employee Behavioural Models}

Maslow's hierarchy of needs is a behavioural theory which details how individuals satisfy personal needs in the context of their work (Allen et al., 2019). Herzberg (1959) developed a two-dimensional model of factors contributing to employees' attitudes to work, referred to as either hygiene factors or motivators. The hygiene factors include interpersonal relationships, salary, job security, operating conditions, administrative practices in the organisation and benefits provided. The factors referred to as motivators are those which serve to bring about the improved job satisfaction and performance that employers seek as a result of satisfying the employee's needs for self-actualisation in their role. Hackman and Oldham (1980) developed a framework known as the job characteristics model, which serves to identify how particular job characteristics affect employee attitudes, including job satisfaction. Many of the criteria identified in this paradigm align with motivators developed by Herzberg (1959), pinpointing facets of the role of HGV drivers that could be reviewed in an attempt to create greater job satisfaction. In the job characteristics model, five core features are detailed that contribute to how fulfilling and meaningful an employee's work is: task identity, task significance, autonomy, feedback, and skill variety. In this paper, employee behavioural models developed by Maslow (1943), Herzberg (1959) and Hackman and Oldham (1980) provide the central academically recognised frameworks for analysis of employee satisfaction and motivation.

Concerning the job satisfaction levels of professional drivers, attitudes to their environment and other personnel - particularly dispatchers, top management and other drivers in the company - and the recognition systems in place held a significant role in influencing extrinsic job satisfaction among logistics drivers (Wijngaards et al., 2019) Recently hired drivers also have been found to represent a different challenge for managers in maintaining employee satisfaction, and must be given greater consideration in order to reduce turnover rates (LeMay et al., 2009; Mittal et al., 2018). Schulz et al. (2014) found a positive relationship between job satisfaction, organisational commitment and retention rates among truckload drivers. Truck drivers' job satisfaction and 
organisational/occupational commitment can help overcome truck driver shortage and employee turnover (Large et al., 2014).

\subsection{Driver Retention}

Research has noted that low retention rates and labour shortages become very costly issues for transportation companies (Fournier et al., 2012). Considerable research has been carried out on driver recruitment and retention strategies. For instance, Hokey and Emam (2003) recommend that trucking firms consider a multitude of attributes such as a driver's demographic profile (e.g. age), longevity, prior driving experience, union status, and the trucking firm's organisational settings when formulating a successful driver recruitment and retention strategy. Min and Emam (2003) claimed that, due to the complexity of the issue, no stand-alone measure is sufficient in reducing turnover. This can be attributed to the fact that drivers (and employees, generally) are not homogenous in regard to their expectations, needs and beliefs (Taylor et al., 2010). Williams et al. (2011) proposed a segmented view of drivers as a strategy for retention, with drivers categorised by their demographics and the importance of the driver's role. Taylor et al. (2010) argued that the validity of a segmented approach to driver retention, in this case in terms of owneroperators specifically, indicating a 'one size fits all' approach to tackling driver turnover, is unlikely to have successful results. Schulz et al. (2014) stated that psychological capital among drivers correlates strongly with job satisfaction and commitment to their organisation, further outlining the role that psychological components play in maintaining driver employment rates where often relationships can seem solely focused on monetary incentives. The findings of Schulz et al. (2014) represented an opportunity to recruit and retain highperforming drivers, stemming from a greater understanding of psychological capital. To ensure driver retention, performance appraisals need to be transformed. Mittal et al. (2018) proposed strategies for improving driver retention such as driver training, making driving easier with use of technologies, and even offering driver retention programmes.

\subsection{Driver Support Initiatives}

HGV drivers encounter many challenges in their daily operations, stemming from their duty to satisfy the needs of their own organisation, shippers and receivers while maintaining safety standards and complying with extensive regulations (Kemp et al., 2013). A case study of truck drivers in a Portuguese logistics company conducted by Sousa and Ramos (2018) found that, in interviews with 
drivers, many cited the demanding and irregular nature of work schedules as a burden of the occupation. Drivers found their erratic schedule put a strain on their ability to balance work and family life. Passey et al. (2014) echoed this point about the strain that irregular work schedules place on drivers. In this case, drivers identified their schedule as an issue in regard to their long-term health. Irregular timetables make maintaining a healthy lifestyle difficult; drivers found time constraints and a lack of energy were barriers to exercising, as well as lack of access to nutritional meals during unsocial hours. Several studies have developed the link between driving as a career and particular health issues such as back disorders, heart disease, obesity, diabetes and respiratory issues (Jensen and Dahl, 2009; Dahl et al., 2009; Angeles et al., 2014). The research conducted by Sousa and Ramos (2018) found that working as a professional driver can be psychologically demanding while exposing drivers to some physical risk due to repetitive motions and associated fixed postures. A similar investigative study into occupational stressors among drivers identified many of the same sources of psychological strain, despite this research taking place in the different context of the long-haul truck driving industry of the United States. Participants in this study identified feelings of isolation, intense pressure to fulfil timely delivery and frustration due to lack of control and fatigue as significant problems in the profession (Shattel et al., 2010). Various sources confirm the link between driver fatigue and road traffic accidents (Hilton et al., 2009; Viscelli, 2018; LeMay and Keller, 2019), while Bergasa et al. (2006) indicate that, in the European freight transport industry, around $60 \%$ of fatal truck accidents can be attributed to a driver's diminished level of vigilance.

The high occupational stress and low standard of care afforded to drivers have been identified as key contributors to mental health issues among drivers, including loneliness, depression and anxiety (Shattell et al., 2012). As with fatigued drivers, drivers dealing with any of the mental health issues detailed have been found to be more likely to be involved in traffic accidents (Hilton et al., 2009).

As the physical and mental health of drivers remains an area of concern in road haulage, Boyce (2016) stated that greater care should be given to driver wellness, particularly so that the current workforce of drivers is given the greatest opportunity to perform to the best of their abilities given the already strained driver resources available, and suggested promoting healthy-eating initiatives and smoking cessation as methods of reducing health problems. Research on health promotion schemes for qualified drivers shows that these initiatives are well-received and garner tangible positive results in the form of improved body 
mass index (BMI) ratings, reduced blood pressure and cholesterol, and increased consideration given by drivers to exercise and balancing their diet (Holmes et al., 1996; Olson et al., 2009; Sorensen et al., 2010; Sendall et al., 2016). The literature regarding initiatives to limit the physical and training issues encountered by HGV drivers is somewhat limited. Further research is needed, although improving driver job satisfaction by reducing the stressors encountered has been identified as an area to consider (Da Silva-Junior et al., 2009; Shattell et al., 2012).

\subsubsection{Driver Wellbeing}

In the human resource management (HRM) literature, there is a fundamental question regarding potential trade-offs between organisational performance and employees' wellbeing in contemporary organisations (Peccei, 2004). Categories concerning drivers' wellbeing at work are frequently encountered in the literature (Van de Voorde et al., 2012; Crizzle et al., 2017; Staats et al., 2017; Maloni et al., 2017; LeMay and Keller, 2019). First, there is happiness-related wellbeing, which is empirically assessed through job satisfaction. Second, there are objective physiological measures and subjective bodily health measures, gauged through job stress. Finally, trust and commitment measures the social wellbeing dimension, which refers to the quality of the relationship between employee and employer. Job satisfaction and commitment in HRM are the main components of wellbeing that are most significantly affected by the HRM practices considered (Maloni et al., 2017; Celma et al., 2018). The level of job satisfaction experienced by workers is an important influence on their health, with the strongest correlation being between job satisfaction and psychological health issues, particularly burnout; poor job satisfaction is found to be a key contributor to burnout or emotional exhaustion (Schulz et al., 2014; Wijngaards et al., 2019). Furthermore, commitment among the members of the supply chain is one of the most fundamental resources (Huo et al., 2015; Mittal et al., 2018; Patrucco et al., 2020). Building commitment as an aspect of the supplychain relationship has a positive effect on sustainable supply-chain performance (Chen et al., 2017). 


\section{Research Methodology}

This research followed a two-stage methodology, involving a large-scale survey and in-depth semi-structured interviews. Quantitative research targets larger samples than qualitative research in order to produce generalizable results. Qualitative research addresses objectives through techniques that allow the researcher to generate in-depth interpretations of phenomena without relying on numerical data, focusing on unearthing new insights and inner meanings (Zikmund et al., 2013).

Having considered the limitations and advantages of using each approach, a two-stage method research strategy was selected, using both quantitative and qualitative approaches independently. This particular mixed-method research approach was chosen due to the associated benefits of triangulation and aid interpretation. Triangulation refers to the use of multiple independent sources of data to validate research findings, whereas aid interpretation refers to the use of qualitative data as a tool to elaborate on the quantitative data collected (Saunders et al., 2009). The mixed methods can be particularly powerful when correctly designed (Golicic and Davis, 2012). The fact that the quantitative and the qualitative research approaches are not only compatible but also complementary underpins calls for additional research studies that use the mixed-methods research approach (Carr et al., 2007).

SPSS (Statistical Package for the Social Sciences) was applied to test the relationships between the factors contributing to driver shortage and job turnover and retention. Thematic analysis was conducted to analyse the causing factors. This is a foundational method for qualitative analysis and is an accessible and theoretically flexible approach to analyse qualitative data (Lee and Lings, 2008).

\subsection{Sample and Data Collection}

Saunders and Lewis (2012) identified questionnaires as an efficient method of collecting data about a constant list of questions from a large number of respondents. For this reason, a questionnaire was developed to be distributed to professional drivers employed in the FTDL sector to gauge their views on their profession. An analytical and descriptive questionnaire, which considered all relevant facets of drivers' views on their roles, was developed for the purpose of collecting quantitative data for analysis. These questionnaires were distributed both individually and within groups when possible. All 
questionnaires were distributed face-to-face to drivers. A total of 130 questionnaires were given to national drivers and international drivers in December 2018 and January 2019 in the Republic of Ireland; 115 questionnaires were collected in February 2019. Four of the questionnaires were not fully completed. After data coding and data screening, 111 questionnaires were deemed useful. The rate of completed questionnaires is $97 \%$. The research was conducted using 111 questionnaires and data analysis with SPSS. Furthermore, five detailed semi-structured interviews were carried out, conducted face to face with the drivers or over the phone, depending on their availability during July/August 2019. The participants included a range of HGV drivers deemed to have subject matter expertise in their respective fields.

\subsection{Data Analysis}

The analysis from the questionnaires was distributed to those currently operating as HGV drivers in freight transport, followed by the findings of the semi-structured interviews conducted with experienced freight transport personnel in relation to the role of HGV drivers. The data collected through questionnaires regarding driver age reaffirms the mature demographic among employed drivers in the country (Expert Group on Future Skills Needs, 2016), reiterating the burden of replacement demand which will soon prevail. Almost $20 \%$ of the drivers surveyed were aged 55 or older (see Figure 1 ), while $17 \%$ of drivers surveyed were under the age of 40 . This highlights the profession's relative inability to attract a young labour force. It is important to note that the vast majority of the current samples are middle-aged male adults, in their mid 40 s to mid 50 s. A shortage of drivers continues to cause concern for a sustainable future.

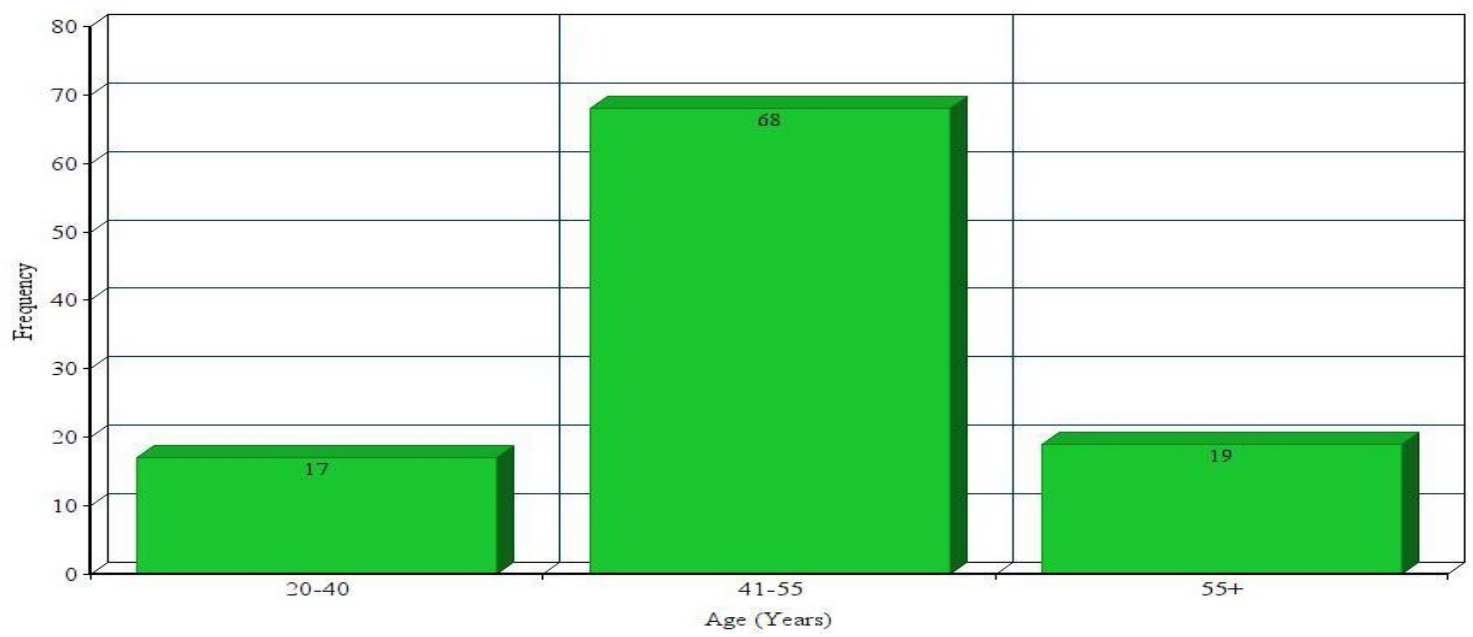

Figure 1. Driver age histogram 
Data gathered from the questionnaires found that over $16 \%$ of participants were working more than 60 hours per week (see Figure 2). Cross-case tabulation analysis found that $33 \%$ of those working over 60 hours were doing so for monetary reasons. Work hours play an important role in employee retention. In an open-ended section of the questionnaire asking drivers for additional comments on what they deem to be the main issues currently facing drivers in the sector, wide-ranging concerns were identified. Drivers mentioned low pay, extensive regulations, pressure to fulfil on-time deliveries and long hours away from home. Other issues were aspects of the role external to the administration of their own organisation such as the facilities made available to drivers throughout the country and the respect afforded to them by colleagues and members of the public. Questionnaire findings also indicated a positive relationship between the length of time working as a professional driver and commitment to the role.

How many hours per week do you work on average?

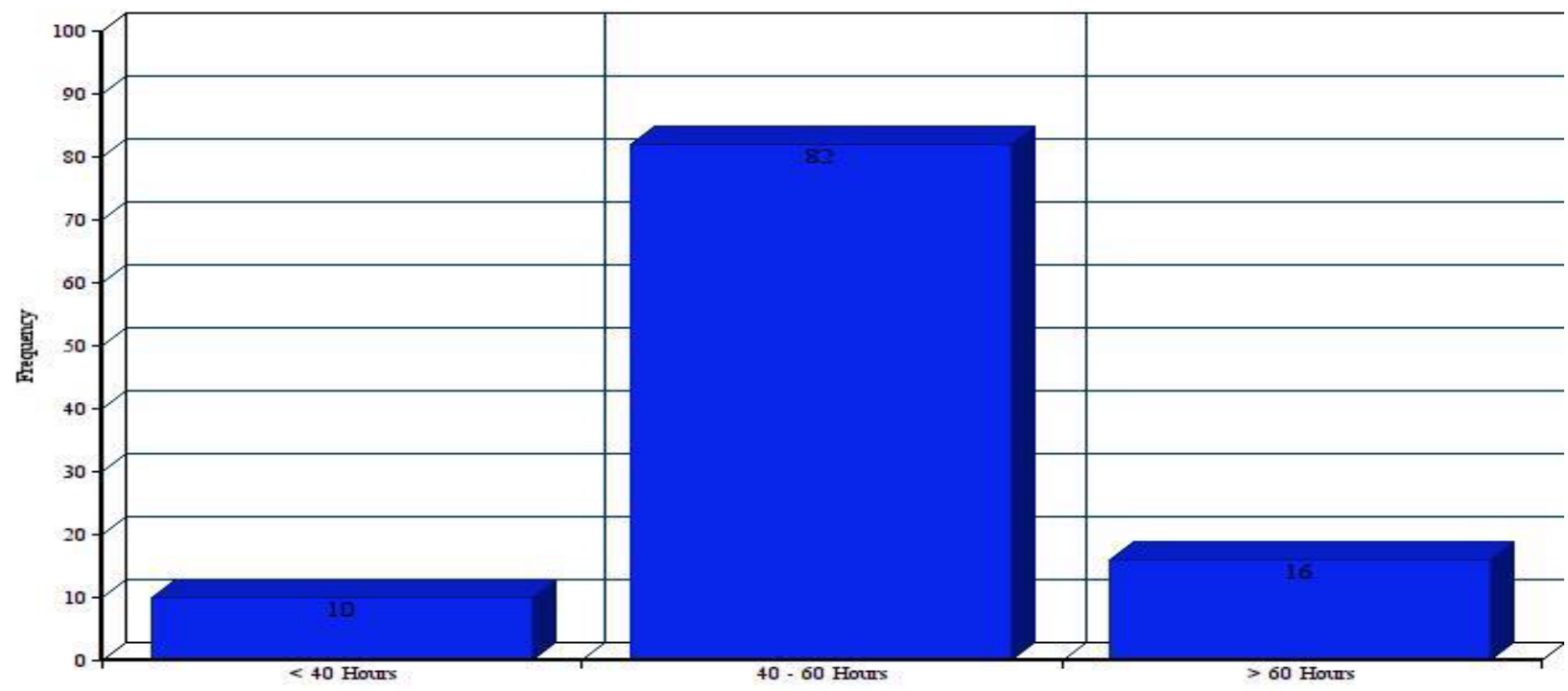

Figure 2. Average hours worked per week

The format for presenting the data gathered through the semi-structured interviews with experienced personnel in the FTDL sector was based on thematic analysis conducted through coding. Braun and Clarke (2006) state that thematic analysis provides a flexible and useful research tool that can provide a rich and detailed, yet complex, account of data. In addition, it provides methods of analysis that should be applied rigorously to the data. It can be used to further 
interpret various aspects of the research topic. As thematic analysis does not require detailed theoretical and technological knowledge of approaches, it is a more accessible form of analysis. However, because thematic analysis is a flexible method, the researcher needs to be clear and explicit about objectives; what the researcher says they are doing needs to match up with what they are actually doing. Thus, the theory and method need to be applied rigorously (Lee and Lings, 2008). There was strong correlation in terms of the answers and attitudes expressed in the interview process. There was overwhelming awareness of the current phenomenon of driver shortage and an agreement that change needs to occur. However, it was widely acknowledged that there is a lack of ownership among state agencies and professional industry bodies, with neither taking action - ultimately to the detriment of this cohort of drivers, to other vulnerable road users and to the freight and logistics sector as a whole. Following transcription of the interview materials, analysis in this paper focused on what the interviewees explained about themes. These themes, listed in Figure 3 , capture key findings from the data in relation to the research purpose.

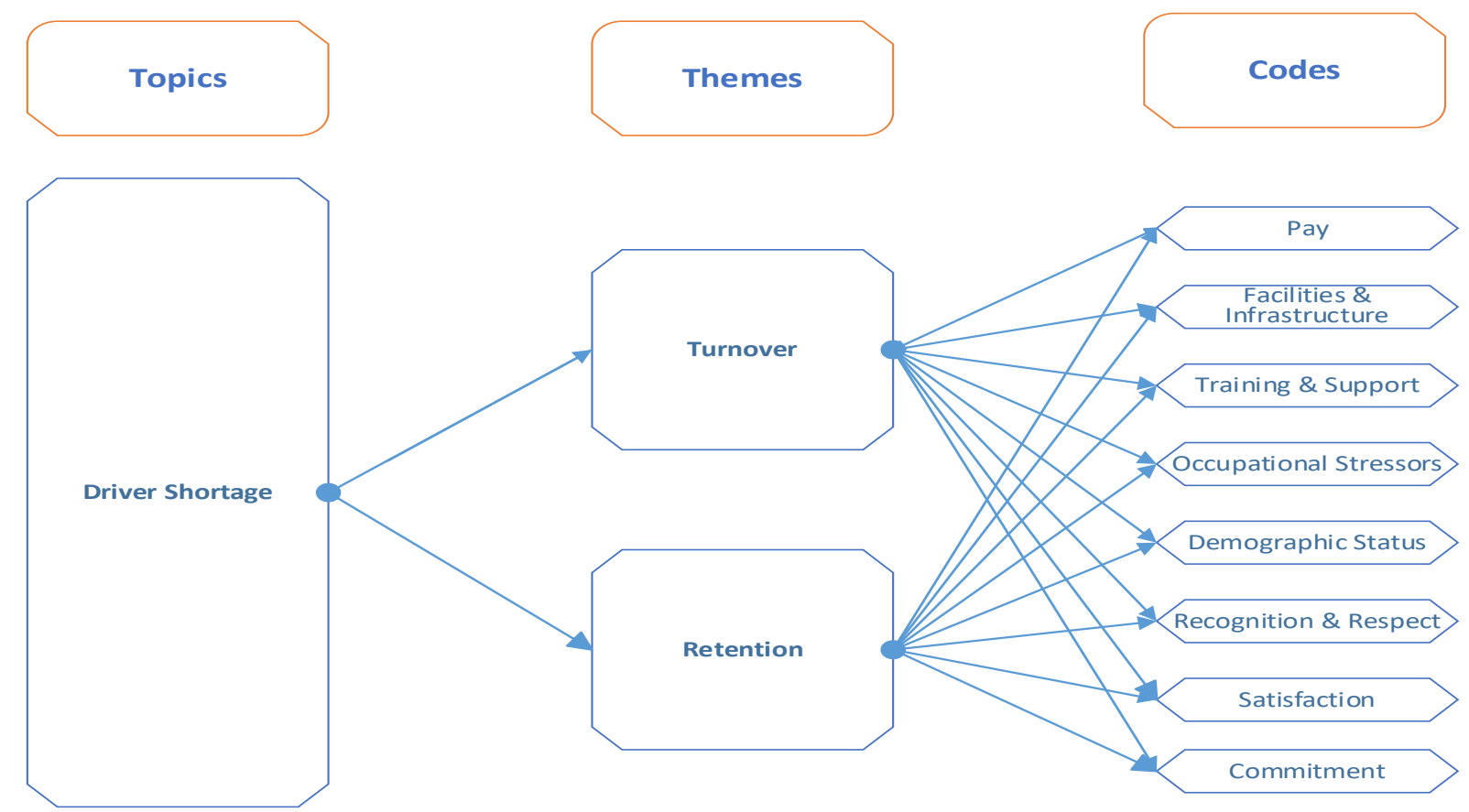

Figure 3. Codes-to-theory model of this research 


\section{Discussion of Findings}

The discussion analyses and elaborates on the findings of both the questionnaires collected and the semi-structured interviews collectively, with consideration given to the literature previously reviewed, in order to identify theory that is applicable to the findings and to provide greater understanding of driver shortage in the FTDL sector.

The data collected through the questionnaires found that $44 \%$ of drivers choose this career because they like driving, while $19 \%$ do so because they believe it is secure employment. Native-English-speaking drivers work many more hours than the non-native-English-speaking drivers. Drivers who are employees work many more hours than drivers who are owner operators. Surprisingly, the majority of drivers are working overtime, even though fatigued drivers and drivers suffering from mental health issues are found to be more likely to be involved in traffic accidents (Hilton et al., 2009; Viscelli, 2018; LeMay and Keller, 2019).

According to the data analysis, around 70\% of respondents are working 41-60 hours per week and the majority of these are working overtime (week days and weekends). Interestingly, $16 \%$ of drivers working in excess of 60 hours a week are doing so for financial reasons. This highlights the view of interviewees that the pay received by drivers is inadequate. National delivery drivers are paid by kilometre and the number of deliveries. In contrast, for international deliveries, drivers are paid through a combination of hours and salary. The majority of the drivers complete 4-8 deliveries per day. Remuneration of professional drivers is a matter mentioned by all interviewees as being detrimental to recruitment and retention. Concerning the topic of shortfalls in recruitment, the level of pay and benefits provided to drivers was frequently the first area identified by participants. This finding supports the literature, which highlights the fact that insufficient pay is a negative aspect of the profession and is a key contributor to driver turnover (Expert Group on Future Skills Needs, 2015; Staats et al., 2017). This finding is in line with those of Wijngaards et al. (2019) who conducted research on the determinants of happiness among truck drivers. They found that unfair pay in the truck-driving setting might make pay a particularly important determinant for truck drivers' wellbeing.

The majority of participants agreed that driving roles generally attracted those who appreciated the freedom involved in driving for a living or those who enjoyed driving. Hackman and Oldham (1980) noted the importance of some 
level of employee autonomy in maintaining job satisfaction, much of which has been removed within professional driving, according to some participants. Furthermore, the findings generated through the primary qualitative research in terms of driver recruitment, training programmes and institutional support provided to drivers raise several areas of concern when taking into account the behavioural theories referred to above (Hackman and Oldham, 1980; Cheng et al., 2014; Mittal et al. 20018).

Of the participants surveyed, $44 \%$ stated they became drivers due to their love of driving whereas less than $13 \%$ stated that they chose the profession due to the benefits of the role (flexible hours), which could be described as 'hygiene factors' (Herzberg et al., 1959). According to the literature, some level of employee autonomy is important to maintain job satisfaction (Hackman and Oldham, 1980; Wijngaards et al., 2019).

A range of occupational stressors were frequently referred to throughout the interview process. Several factors were identified as contributing to a negative professional experience for drivers such as pressure to fulfil on-time deliveries, rigorous regulations and extended time spent on the road. These factors were identified in both facets of the primary research and in the secondary data as adverse aspects of the profession (Shattel et al., 2010; Passey, et al., 2014; Sousa \& Ramos, 2018).

Because of long hours away from home, social and psychological factors have a significant influence on drivers' job satisfaction. All participants referred to the loneliness that they can experience. Abiding by increasingly strict regulations, irregular work schedules and unfavourable views held by the public towards drivers are other issues identified through the data collection as unsatisfactory elements of the profession. Interview participants frequently mentioned how drivers are perceived and treated both by those within the freight transport and logistics operations and by members of the general public. It was asserted that drivers need to be treated with more respect and dignity. Recognition of drivers' efforts by management, including simple gestures of appreciation, were found to be hugely significant in terms of driver retention. These findings are consistent with Maslow (1943) who recognised how fulfilment of an individual's selfesteem positively affects human motivation. The corollary is also true. Individuals who experience a lack of respect and who are not seen as unique individuals tend to have feelings of dissatisfaction (Herzberg et al., 1959).

The poor standard of facilities provided to drivers (the country's service stations) 
was an issue frequently mentioned throughout the interview process. When considering the hygiene factors of the role, as noted by Herzberg (1959), these poorly provided and maintained facilities can be deemed significant factors in adding to job dissatisfaction among drivers, given the frequency with which they must avail of these services. The substandard amenities encountered by drivers, as mentioned in the literature, contribute to unsatisfactory operating conditions. Hackman and Oldham (1980) and Wijngaards et al. (2019) noted the importance of some level of employee autonomy in maintaining job satisfaction, but much of this autonomy has been removed in professional driving. Training programmes and institutional support provided to drivers raise several areas of concern when taking into account the behavioural theories outlined in Maslow (1943) and Bag and Anand (2014), identifying achievement and progression in an individual's role as significant influences on motivation.

Most of the participants felt that very little regard was given to their health as no facilities are provided at service stations for exercise, no education is provided to them on how to maintain a balanced diet, and no institutional support is provided to promote positive mental health. This finding supports Boyce (2016) who advocates that greater care should be given to driver wellness, particularly so that the current workforce of drivers is given the greatest opportunity to perform to the best of their abilities. The promotion of healthyeating initiatives and smoking cessation are recommended as methods of reducing health problems. The finding is also in keeping with Maloni et al. (2017) and Celma et al. (2018) who found that job satisfaction and the commitment of management are the main components of wellbeing that are most significantly affected by the HRM practices considered. Despite widespread knowledge and numerous publications outlining the detrimental effects that working as a driver can have on both the physical and mental health of drivers, considerable research illustrates that very few initiatives to support driver wellbeing in these matters has been provided (Dahl et al., 2009; Jensen and Dahl, 2009; Shattell et al., 2012; Angeles et al., 2014).

The data analysis also found that there is a relationship between the drivers' age group and job satisfaction, and between the length of time working as a professional HGV driver and job satisfaction. A borderline significant trend relationship between training/professional development and job commitment was found (see Table 3). Older drivers were found to have greater commitment to the position and to experience greater satisfaction in carrying out their duties; a positive relationship exists between the length of time working as a professional driver and commitment to the role. This supports the theory 
proposed in multiple academic journals that the driver demographic is the central factor behind driver turnover rates (Min and Emam, 2003). This result is also in line with Schulz et al. (2014) who found a positive relationship between job satisfaction, organisational commitment and retention rates in truckload drivers. Truck drivers' job satisfaction and organisational/occupational commitment can help overcome the truck driver shortage and employee turnover (Large et al., 2014). 
Table 1. Sample characteristics

\begin{tabular}{|ll|}
\hline Drivers' age group & $\%$ \\
\hline $20-40$ & 17 \\
$41-55$ & 68 \\
$55+$ & 15 \\
\hline
\end{tabular}

\begin{tabular}{|lc|}
\hline $\begin{array}{l}\text { Length of time working as a } \\
\text { professional HGV driver }\end{array}$ & $\%$ \\
\hline 1-6 months & 5 \\
Less than 1 year & 18 \\
1-3 years & 37 \\
4-10 years & 24 \\
Over 10 years & 16 \\
\hline
\end{tabular}

$*_{\mathrm{n}}=111$

Table 2. Item loadings and reliabilities

\section{Job Satisfaction}

I feel encouraged to come up with new and better ways of doing things.

My work gives me a feeling of personal accomplishment. My supervisor values me.

The company does an excellent job of keeping employees informed about matters affecting drivers.

My company provides me with a clear path for career advancement. Overall, I am satisfied with my job.

\section{Job Commitment}

I am loyal to my manager. Even if I could, I would not leave my job because I like being associated with my manager. I want to remain a member of my firm, because I genuinely enjoy my work.

I expect to work for this firm for a long time. My positive feelings towards the manager is a major reason I continue working with it.

I see this job as a long-term opportunity. I am very committed to my job.

\section{Job Retention}

I don't plan to drive for this company much longer.

I wish I was driving for some other company.

I often think about quitting my job.

It is likely that I will actually look for a new job in the next year.

\section{Professional Training \& Development}

I have received safe and secure loading training in the past 12 months.

I have received training on the correct use of working time.

CPC training raised my awareness of safety issues.

CPC training has helped me become a better driver.

My employer provided induction training for me when I

started working with them.

$0.930 \quad 0.913$

0.855

36.814

0.901

61.324

0.902

61.049

0.862

46.368

0.931

0.974

0.965

$0.845 \quad 38.824$

$0.904 \quad 62.354$

$0.906 \quad 60.049$

$0.872 \quad 46.478$

$0.910 \quad 66.53$

$0.903 \quad 63.166$

$0.910 \quad 72.844$

$0.815 \quad 33.226$

$0.844 \quad 39.499$

$0.894 \quad 57.032$

$0.902 \quad 61.385$

$0.883 \quad 52.467$

$0.912 \quad 66.322$ 
Table 3. Correlations

\begin{tabular}{|l|c|c|c|c|}
\hline & $\begin{array}{c}\text { Job } \\
\text { Satisfaction }\end{array}$ & $\begin{array}{c}\text { Job } \\
\text { Commitment }\end{array}$ & $\begin{array}{c}\text { Job } \\
\text { Retention }\end{array}$ & $\begin{array}{c}\text { Professional Training } \\
\text { Development }\end{array}$ \\
\hline Job Satisfaction & 0.986 & & & \\
\hline Job Commitment & 0.835 & 0.889 & & \\
\hline Job Retention & 0.934 & 0.804 & 0.887 & 0.926 \\
\hline $\begin{array}{l}\text { Professional Training \& } \\
\text { Development }\end{array}$ & 0.882 & 0.905 & 0.886 & \\
\hline
\end{tabular}

* The diagonal holds the square root of the Average Variance Extracted. All correlations are significant at $1 \%$ level.

\section{Theoretical and Managerial Implications}

This study has addressed the issues contributing to the driver shortage and analysed the relationship between these issues and driver retention by conducting two-stage research. Such research contributes significantly to the FTDL sector, and also provides theoretical and practical knowledge in order to attract and retain a sustainable labour force of drivers. By uncovering the factors contributing to driver shortage, this study fills a gap in the literature. It is one of the very few studies concerning a 'people dimension' in logistics and supplychain management studies (Sweeney, 2013). Specifically, it examines the general lack of understanding of HGV drivers' viewpoints in the context of logistics and supply-chain management.

This study also recommends future research on how to develop better professional status for drivers (McKinnon et al, 2017; Mittal et al., 2018). Despite much evidence that initiatives promoting driver wellbeing in terms of physical and mental health are generally well received and garner positive tangible results, very little support or education is provided to drivers in this regard. Considering the well-documented physical and psychological health issues drivers may experience due to the nature of the profession, this is an area that requires greater attention (Shattell et al., 2012; Angeles et al., 2014; LeMay \& Keller, 2019; Wijngaards et al., 2019). This study addresses human resource management issues in relation to job turnover, job retention and wellbeing specific to supply-chain management studies in regard to the HGV driver shortage. It recommends future research on a combination of pertinent human resource and relational measures to ensure overall sustainable supply-chain performance (LeMay \& Keller, 2019; Wijngaards et al., 2019).

Assessing HGV drivers is dependent on identifying a co-operative FTDL sector that is willing to participate in research. This paper is the first of its kind in so far as it seeks to analyse the driver shortage problem considering it as a whole and 
from a specifically Irish perspective. Therefore, it was key to gain access to these companies in Ireland early in the process. This research builds on previous work by the authors collaborating with the Freight Transport Association of Ireland.

The study also addresses a deficit in research on driver issues in the Irish FTDL sector. For nearly half a century, the turnover of truck drivers has been a major issue in supply chain management. This research provides driver managers with the knowledge to better understand and to more adequately provide for the needs and welfare of truck drivers in order to improve sustainable supply-chain performance, which reflects the key global challenges in sustainability. The study proposes a framework for evaluating whether issues are addressed that offer marginal improvements toward sustainability and that fill the gap in the current research.

\section{Recommendation and Conclusion}

Within the overarching topic of driver shortage, this paper has analysed and discussed the challenges encountered by drivers in regard to operational and social aspects of their role, the key contributors to driver recruitment and retention, and how different aspects of the profession may affect a driver's motivation and satisfaction in their position. Several aspects of the HGV drivers' profession can be pinpointed as issues which negatively influence retention. The degree of respect afforded to drivers in all aspects of their duties, the perceived status of driving roles, the insufficient standard of facilities provided to drivers and the operational burdens frequently experienced can all be considered to be hindrances in creating gratifying operating conditions. Furthermore, a lack of opportunity for progression and advancement is an area open to improvement as it discourages potential entrants. In addition, a greater emphasis on regulations was also noted as an aspect making the role less appealing than it once was.

Enhancing the wellbeing of professional drivers in the FTDL sector is essential. There is no panacea for the problems facing professional drivers and their wellbeing, but several measures can be taken by regulatory and industry stakeholders in order to address the current situation.

The method for recruiting drivers needs to be examined, and the system needs to be more professional, with the opportunity for career progression. While a driver's Certificate of Professional Competence has been implemented in recent years, it is a very broad programme which is not tailored to a specific operator's 
needs and pays little more than lip service to the subject of driver wellbeing. Clear measurable training guidelines and qualifications would professionalise this occupation and make it much more attractive to new entrants. Training, education and upskilling are key to having a well-informed, well-educated and dynamic workforce who feel empowered and recognised for the part they play. Driving apprenticeship programmes would also be hugely beneficial in creating a sustainable workforce. A change in pay structure that would be commensurate with the training and qualifications gained would also be beneficial. This would also have a positive effect on the public perception of the professional sector.

Despite the large number of driving professionals in Ireland, theirs is a voice which is not being heard by their employers or indeed legislators and policymakers. They are unhappy in their role but unable to effect any change for the better. Other sectors in Ireland, such as agriculture, exert a strong lobbying power; a similar collective group would be very beneficial to professional drivers.

This paper pinpoints procedures to combat unsatisfactory aspects of the role, using the academically recognised behavioural theories identified in the report as frameworks: Maslow's hierarchy of needs, Herzberg's two-factor model and Hackman and Oldham's (1980) job characteristics model. It is high time to review the standard of facilities provided to drivers in Ireland. Facilities provided to drivers by both clients and at service stations are of insufficient standard to meet drivers' requirements. Reviewing these facilities comparatively with their European counterparts may highlight areas for potential improvements in order to create more satisfying working conditions for drivers. There needs to be a reassessment of driver training and education practices. Repetitive and monotonous training courses, which drivers are required to partake in annually, are mentioned as an area of dissatisfaction for drivers throughout the data collection. A redeployment of the sector's resources to better educate drivers on some of the soft skills required or on their own physical and mental health would be beneficial. Not only would the changes recommended above extend the duration for which drivers would be capable of performing their duties; they would also display a greater industry-wide consideration for their wellbeing, giving recognition to the important, and often taxing, role drivers play in freight transport. There is also a need to create infrastructure for young applicants to progress in their career through driving. The recruitment of young drivers with the opportunity given to earn while they learn and to progress in their careers, as is the case in other professions, is lacking in professional driving. Creating national or private driving apprenticeship programmes would help to attract a sustainable workforce. 
Although this study makes important contributions to both theory and practice, there are a few limitations that open up avenues for further research. Research conducted into the current shortage of drivers, particularly in Ireland and Europe, is limited; thus research with a greater range of participants is required, or research which places greater focus on the collection of quantitative data in order to analyse the views of a greater sample size. Throughout the primary research, the change in the perceived status of driving as a profession was mentioned frequently. Further research needs to be done into aspects of the role which have changed and how women's participation in HGV commercial driving could reduce the current driver shortage.

\section{References}

Allen, J., Muñoz, J. C., Ortúzar, J. D. (2019). Understanding public transport satisfaction: Using Maslow's hierarchy of (transit) needs. Transport Policy, 81, 75-94.

Alsaraireh, F., Quinn Griffin, M. T., Ziehm, S. R., \& Fitzpatrick, J. J. (2014). Job satisfaction and turnover intention among Jordanian nurses in psychiatric units. International Journal of Mental Health Nursing, 23(5), 460-467.

Angeles, R., McDonough, B., Howard, M., Dolovich, L., Marzanek-Lefebvre, F., Qian, H., \& Riva, J. J. (2014). Primary health care needs for a priority population: A survey of professional truck drivers. Work 49(2), 175-181.

Bag, S., \& Anand, N. (2014). Retention of long distance company truck drivers in India. International Journal of Operations and Logistics Management, 3(3), 222-240.

Bergasa, L. M., Nuevo, J., Sotelo, M.A. Barea, R., Lopez, M.E. (2006) Does truck driver health and wellness deserve more attention? IEEE Transportation on Intelligent Transportation System, 7(1), 6377.

Berman, J., (2019). Bureau of Labor Statistics report downplays impact and severity of truck driver shortage. Logistics Management, 58(4), 60-63.

Boyce, W. S. (2016). Does truck driver health and wellness deserve more attention? Journal of Transport \& Health, 3(1), 124-128.

Braun, V., Clarke, V. (2006). Using thematic analysis in Psychology Qualitative Research in Psychology 3, 77-101.

Carr, L. T. (1994). The strengths and weaknesses of quantitative and qualitative research: What method for nursing? Journal of Advanced Nursing, 20(4), 716-721.

Celma, D., Martinez-Garcia, E., Raya, J. M. (2018). Socially responsible HR practices and their effects on employees' wellbeing: Empirical evidence from Catalonia, Spain. European Research on Management and Business Economics, 24 (2018) 82-89.

Cheng, L., Harris, C., Chou, P., \& Simons, K. (2014). Driver shortage during economic Recovery: Supply chain challenges in the US. Journal of International Management Studies, 14(1), 77-86

Costello, B. (2017). Truck Driver Shortage Analysis 2017, American Trucking Associations, Alexandria, VA. 
Crizzle, A.M., Bigelow, P., Adams, D., Gooderham, S., Myers, A.M., Thiffault, P. (2017). Health and wellness of long-haul truck and bus drivers: A systematic literature review and directions for future research. Journal of Transport \& Health, 7, 90-109.

Crostello, B., \& Suarez, R. (2015). Truck driver storage analysis 2015. Arington, VA: The American Trucking Associations.

Da Silva-Junior, F., Nunes de Pinho, R., De Mello, M. T., Sales de Bruin, V., \& Carvelhedo de Bruin, P. (2009). Risk factors for depression in truck drivers. Social Psychiatry and Psychiatric Epidemiology 44(125).

Dahl, S., Kaerlev, L., Jensen, A., Tuchsen, F., Hannerz, H., Nielsen, P., \& Olsen, J. (2009). Hospitalization for lifestyle related diseases in long haul drivers compared with other truck drivers and the working population at large. Work 33(3), 345-353.

De Croon, E., Sluiter, J. K., Blonk, R. W., Broersen, J. P., \& Frings-Dresen, M. H. (2004). Stressful Work, Psychological Job Strain, and Turnover: A 2-Year Prospective Cohort Study of Truck Drivers. Journal of Applied Psychology 89(3), 442-454.

Douglas, M.A. and Swartz, S.M. (2016). Career stage and truck drivers' regulatory attitudes. International Journal of Logistics Management, 27(3), 686-706.

EGFSN. (2015). Addressing the Demand for Skills in the Freight Transport, Distribution and Logistics Sector in Ireland 2015-2020.

Fournier, P.-S., Lamontagne, S., Gagnon, J., 2012. Interactions between dispatchers and truck drivers in a high turnover context. Relat. Indus. 67,263-282.

Gawal, J. E. (1997). Herzberg's theory of hygiene and Maslow's hierarchy of needs. Practical Assessment, Research \& Evaluation 5(11), November.

Golicic, S., Davis, F. (2012). Implementing mixed methods research in supply chain management. International Journal of Physical Distribution \& Logistics Management, 42(8/9), 726-741.

Hackman, J. R., \& Oldham, G. R. (1980). Work Redesign. Reading, MA: Addison-Wesley.

Han, C., Otto, J., Dresner, M., (2019). A Typological Analysis of US Transportation and Logistics Jobs: Automation and Prospects. Transportation Journal, 58(4), 323-341.

Herzberg, F., Mausner, B., \& Snyderman, B. B. (1959). The Motivation to Work, 2nd Edition. New York: John Wiley \& Sons.

Hilton, M., Staddon, Z., Sheridan, J., Judith; Whiteford, H.A. (2009) The impact of mental health symptoms on heavy goods vehicle drivers' performance. Accident Analysis \& Prevention, 41(3), 453461.

Hohenstein, N., Feisel, E., Hartmann. E. (2014) Human resource management issues in supply chain management research: A systematic literature review from 1998 to 2014. International Journal of Physical Distribution \& Logistics Management, 44(4). 434-463.

Hokey, M., \& Emam, A. (2003). Developing the profiles of truck drivers for their successful Holmes, S. M., Power, M. L., \& Walter, C. K. (1996). A Motor Carrier Wellness Program: Development and Testing. Transportation Journal, 35(3), 33-48.

Huo, B.F. Zhang, C., Zhao, X., 2015. The effect of IT and relationship commitment on supply chain coordination: A contingency and configuration approach. Information Management 52(6), 728-740.

Jensen, A., \& Dahl, S. (2009). Truck drivers hours-of-service regulations and occupational health. Work 33(3), 363-368. 
Kahneman, D., Deaton, A., 2010. High income improves evaluation of life but not emotional well-being. In: Proceedings of the National Academy of Sciences, 16489-16493.

Kemp, E., Kopp, S. W., \& Kemp Jr., E. C. (2013). Examining the Influence of Role Stressors and Emotional Exhaustion on Organizational Commitment and Identification in Professional Truck Drivers. Journal of Business Logistics, 34(1), 33-45.

King, M. (2019) European truck driver shortage now major problem for shippers. Online resource: https://www.lloydsloadinglist.com/freight-directory/news/European-truck-driver-shortage-nowmajor-problem-for-shippers/74206.htm\#.XrwFvVxKjlU

Kubanova, S., Kubasakova, I. (2020). Security Risk in Trucking Sector. Transportation Research Procedia, 44, 234-239.

Kudo, T., Belzer, M.H. (2019). The association between truck driver compensation and safety performance. Safety Science 120, 447-455.

Kumar, R. (2015). Just a piece of legislation! Lackadaisical roll-out. Drivers Duniya, 1(1), 6-8.

Lambert, E. G., Hogan, N. L., \& Barton, S. M. (2001). The impact of job satisfaction on turnover intent: a test of a structural measurement model using a national sample of workers. The Social Science Journal, 38(2), 233-250.

Large, R. O., Breitling, T., \& Kramer, N. (2014). Driver shortage and Fluctuation: Occupational and organizational commitment of truck drivers. Supply Chain Forum: International Journal, 15(3), 66-72.

Lee, N., Lings, I., 2008. Doing Business Research: A guide to theory and practice, SAGE Publication Ltd. London.

Lemay, S. A., \& Taylor, G. S. (1988). Truck driver Recruitment: Some workable strategies. Transportation Journal, 28(1), 15-22.

LeMay, S. A., Johnson, L., Williams, Z., \& Garver, M. (2013). The causes of truck driver intent-to-quit: a best-fit regression model. International Journal of Commerce and Management 23(3), 262-272.

LeMay, S. A., Williams, Z., \& Garver, M. (2009). A Triadic View of Truck Driver Satisfaction. Journal of Transportation Management, 21(2), 1-16.

LeMay, S. Keller, S. (2019) Fifty years inside the minds of truck drivers. International Journal of Physical Distribution \& Logistics Management, 49 (6), 626-643.

Luthans, F., Youssef, C. M., \& Avolio, B. J. (2007). Psychological Capital: Developing the Human Competitive Edge. London: Oxford University Press.

Maloni, M. J., Campbell, S.C., Gligor, D.M., Scherrer, C.R. Boyd, E. M. Exploring the effects of workforce level on supply chain job satisfaction and industry commitment. The International Journal of Logistics Management, 28(4), 1294-1318.

Maslow, A. H. (1943). A Theory of Human Motivation. Psychological Review, 50, 370-396.

McKinnon, A. (2006). Life without trucks: The impact of a temporary disruption of road freight transport on a national economy. Journal of Business Logistics, 27(2), 227-250.

McKinnon, A., Floethmann, C., Hoberg, K., \& Busch, C. (2017). Logistics Competencies, Skills and Training: A Global Overview. The World Bank.

Mello, J. E., Hunt, C. S., Mello, A. L., (2018). Driver Control Practices: The Voice of the Driver. Transportation Journal. 57(1), 53-82.

Miller, J. (2017), A multivariate time-series examination of motor carrier safety behaviors, Journal of Business Logistics, 38(4), 266-289. 
Min, H., \& Emam, A. (2003). Developing the profiles of truck drivers for their successful recruitment and retention: A data mining approach. International Journal of Physical Distribution \& Logistics Management, 33(2), 149-162.

Mittal, N., Udayakumar, P.D., Raghuram, G., Bajaj, N. (2018). The endemic issue of truck driver shortage - A comparative study between India and the United States. Research in Transportation Economics, 71, 76-84.

Olson, R., Anger, W. K., \& Elliot, D. L. (2009). A New Health Promotion Model for Lone Workers: Results of the Safety \& Health Involvement For Truckers (SHIFT) Pilot Study. Journal of occupational \& environmental medicine, 51(11), 1233-1246.

Passey, D. G., Robbins, R., Hegmann, K. T., Ott, U., Thiese, M., Garg, A., Murtaugh, M. A. (2014). Long haul truck drivers' views on the barriers and facilitators to healthy eating and physical activity: $A$ qualitative study. International journal of workplace health management, 7(2), 121-135.

Patrucco, A. S, Moretto, A., Luzzini, D., Glas, A.H.(2020). Obtaining supplier commitment: antecedents and performance outcomes. International Journal of Production Economics, 220, 1-11.

Peccei, R. (2004). Human resource management and the search for happy workplace. Inaugural address of Erasmus Research Institute of Management. Erasmus University Rotterdam.

Prockl, G., Teller, C., Kotzab, H. and Angell, R. (2017). Antecedents of truck drivers' job satisfaction and retention proneness. Journal of Business Logistics, 38(3), 184-196

Rakowski, J. P., Southern, R. N., \& Godwin, L. R. (1989). Motor Carrier road driver recruitment in a time of shortages. Transportation Journal, 28(4), 42-48.

recruitment and retention: A data mining approach. International Journal of Physical Distribution \& Logistics Management, 33(2), 149-162.

Richard, M. D., LeMay, S., \& Taylor, G. S. (1995). A factor-analytic logit approach to truck driver turnover. Journal of Business Logistics, 16(1), 281-298.

Saunders, M., \& Lewis, P. (2012). Doing research in Business \& Management, 1st publication. Pearson Education Ltd. Prentice Hall, UK.

Saunders, M., Lewis, P., \& Thornhill , A. (2012). Research Methods for Business Students 6th Edition. Pearson Education Limited.

Saunders, M., Lewis, P., \& Thornhill, A. (2009). Research Methods for Business Students 5th Edition. London: FT Prentice Hall.

Schulz, S. A., Luthans, K. W., \& Messersmith, J. G. (2014). Psychological capital: A new tool for driver retention. International Journal of Physical Distribution \& Logistics Management 44(8/9), 621-634.

Scott, S., Burnette, M., Dittman, P., Stank, T. and Autry, C. (2015). Supply chain talent: Our most important resource. Available at: www.blog.ryder.com/2015/05/supply-chain-talentmanagement/ (accessed August 12, 2015).

Sekaran, U., \& Bougie, R. (2010). Research Methods for Business - A Skill Building Approach. 5th Edition . John Wiley \& Sons.

Sendall, M. C., Crane, P., McCosker, L., Biggs, H. C., Fleming, M., \& Rowland, B. (2016). Workplace interventions to improve truck drivers' health knowledge, behaviours and selfreported outcomes. Road and Transport Research, 25(1), 31-43.

Shattel, M., Apostolopoulus, Y., Sonmez, S., \& Griffin, M. (2010). Occupational Stressors and the Mental Health of Truckers. Issues in Mental Health Nursing, 31(9), 561-568. 
Shattell, M., Apostolopoulos, Y., Collins, C., Sonmez, S., \& Fehrenbacher, C. (2012). Trucking Organization and Mental Health Disorders of Truck Drivers. Issues in Mental Health Nursing, 33(7), 436444.

Sorensen, G., Stoddard, A., Quintiliani, L., Ebbeling, C., Nagler, E., Yang, M., Wallace, L. (2010). Tobacco use cessation and weight management among motor freight workers: Results of the Gear Up for Health Study. Cancer Causes and Control, 21(12), 2113-2122.

Sousa, I. C., \& Ramos, S. (2018). Working conditions, health and retirement intentions: a case study of truck drivers. International journal of workplace health management, 11(3), 114-129.

Staats, U. Lohaus, D., Woitschek, M. (2017). Fighting against a shortage of truck drivers in logistics: Measures that employers can take to promote drivers' work ability and health. Work, 58, 383-397.

Sweeney, E. (2013). The People Dimension in Logistics \& Supply Chain Management - It's role and Importance. In R. Passaro, \& A. Thomas, Supply Chain Management: Perspectives, Issues and Cases, 73-82. Milan: McGraw-Hill.

Taylor, G. S., Garver, M. S., \& Williams, Z. (2010). Owner operators: employing a segmentation approach to improve retention. The International Journal of Logistics Management 21(2), 207-229.

Van de Voorde, K., Paauwe, J., \& Van Veldhoven, M. (2012). Employee wellbeing and the HRMorganizational performance relationship: A review of quantitative studies. International Journal of Management Reviews, 14(4), 391-407.

Viscelli, S. (2018) Driverless? Autonomous Trucks and the Future of the American Trucker.

Wijngaards, I., Hendriks, M., Burger, M.J., Wijngaards, J., Hendriks, M., Martijn J. Burger, M. J. (2019). Steering towards happiness: An experience sampling study on the determinants of happiness of truck drivers. Transportation Research Part A 128, 131-148.

Williams, Z., Garver, M.S. and Stephen Taylor, G. (2011). Understanding truck driver need-based segments: creating a strategy for retention, Journal of Business Logistics, 32(2), 194-208.

Wowak., K., Craighead, C. W., Ketchen Jr D., Hult, G.T. M. (2013) Supply Chain Knowledge and Performance: A Meta-Analysis. Decision Sciences, 44(5), 843-875.

Wrenn, C. A. (2017). Can Autonomous Technology Reduce the Driver Shortage in the Commercial Trucking Industry? (Doctoral Dissertation, Doctoral dissertation, California Southern University).

Zikmund, W. G., Babin, B. J., Carr, J. C., \& Griffin, M. (2013). Business Research Methods, Ninth International Edition. South-Western Cengage. 